\title{
Anatomia foliar de cinco espécies de Polygala de restinga e cerrado 1
} Leaf anatomy of five Polygala species (Polygalaceae) from restinga and cerrado

\author{
Ana Cristina Andrade de Aguiar-Dias ${ }^{2,3,4}$, Kikyo Yamamoto $^{2}$ \& Marília de Moraes Castro ${ }^{3}$
}

\begin{abstract}
Resumo
A plasticidade ecológica observada em plantas que ocupam diferentes formações vegetais é frequentemente acompanhada por variações morfológicas, sendo a folha o órgão vegetativo com a maior variação estrutural. Diante disso, cinco espécies de Polygala L. ocorrentes em restinga e cerrado do Estado de São Paulo tiveram a anatomia da folha analisada com o objetivo de efetuar um inventário dos seus principais caracteres e descrever sua estrutura, com o propósito de compará-las, e de avaliar se é possível evidenciar padrões estruturais comuns às condições ecológicas de ambas as formações vegetacionais. As espécies pesquisadas foram: P. cyparissias A.St. -Hil. \& Moq., P. laureola A.St.-Hil. \& Moq., P. paniculata L., encontradas em restinga; $P$. angulata DC. e $P$. violacea Aubl. emend. Marques, que ocorrem em campo cerrado e em margem de cerradão, respectivamente. A região mediana da lâmina foliar e a região proximal do pecíolo de cada folha foram processadas segundo as técnicas usuais para microscopia eletrônica de varredura e de luz. Os resultados obtidos evidenciam dois padrões estruturais comuns às espécies procedentes das formações de restinga e cerrado: características mesomórficas são observadas em $P$. laureola, $P$. paniculata e $P$. violacea, e xeromórficas em $P$. cyparissias e $P$. angulata.
\end{abstract}

Palavras-chave: anatomia foliar, cerrado, Polygalaceae, restinga, São Paulo.

\begin{abstract}
The ecological plasticity observed in plants that inhabit different vegetation formations is often accompanied by morphological variations, the leaf being the vegetative organ with the greatest structural variation. In view of this concept, the leaf anatomy of five species of Polygala L. occurring in restinga (sandy coastal plain) and cerrado (savanna) areas in the state of São Paulo were analyzed in order to inventory their principal characters and describe their leaf structure, to thus compare them and assess the possibility of verifying structural patterns common to the ecological conditions of both vegetation formations. The species studied were: . cyparissias A.St.-Hil. \& Moq., P. laureola A.St.-Hil. \& Moq., P. paniculata L. found in restinga, and P. angulata DC. and $P$. violacea Aubl. emend. Marques occurring in campo cerrado and cerradão margin areas, respectively. The middle region of the leaf blade and petiole proximal region of each leaf were processed following the usual techniques for scanning electron and light microscopy. The results show two structural patterns common to the species from the restinga and cerrado area formations: mesomorphic characteristics are observed in P. laureola, P. paniculata, and P. violacea, and xeromorphic in P. cyparissias and P. angulata.
\end{abstract}

Key words: leaf anatomy, cerrado, Polygalaceae, restinga, São Paulo.

\section{Introdução}

A plasticidade ecológica observada em plantas que ocupam diferentes formações vegetais é freqüentemente acompanhada por variações morfológicas, sendo a folha é o órgão vegetativo que apresenta maior variação estrutural em resposta às alterações ambientais (Dickison 2000). O estudo da anatomia foliar pode fornecer importantes evidências para o conhecimento de padrões estruturais observados em espécies de diferentes tipos de habitat (Gibson 1996).

\footnotetext{
${ }^{1}$ Parte da tese de Doutorado da primeira autora.

${ }^{2}$ Universidade Estadual de Campinas, Instituto de Biologia, Depto. Biologia Vegetal, C.P. 6109, 13083-970 Campinas, SP, Brasil.

${ }^{3}$ Universidade Federal do Pará, Instituto de Ciências Biológicas, R. Augusto Corrêa 1, 66075-110, Belém, PA, Brasil.

${ }^{4}$ Autor para correspondência: acaaguiar@yahoo.com.br
} 
A restinga e o cerrado, dois biomas que ocupam grande área territorial no Brasil, são formações complexas que compreendem diversos tipos de habitat com grande variação nas condições abióticas, tais como: intensidade de radiação luminosa, disponibilidade hídrica, temperatura e tipos de solo (Mantovani \& Martins 1993; Assis 1999). Grande parte dos estudos que investigam estes biomas é de cunho florístico ou fitossociológico (Gibbs et al. 1983; Aguiar \& Aranha Filho 2008). Apesar do elevado número de espécies nestas formações vegetais, a anatomia foliar de seus representantes é relativamente pouco estudada (Morretes \& Ferri 1959; Paviani \& Ferreira 1974; Arruda et al. 2009), dificultando o reconhecimento de padrões estruturais das plantas que ocupam estes tipos de formação vegetal.

Dentre as angiospermas presentes nesses dois biomas estão as Polygalaceae, principalmente as espécies de Polygala L. (Gianotti \& Leitão Filho 1992; Marques \& Gomes 2002). Polygala possui distribuição cosmopolita e ocupam diversas formações vegetais no território brasileiro (Marques 1979; Marques \& Aguiar 2000; Aguiar et al. 2008). A escassez de estudos sobre a anatomia foliar em Polygala, já apontada por Pyykkö (1966), ainda persiste, o que dificulta o entendimento da organização estrutural e dos mecanismos fisiológicos apresentados por suas espécies, o que contrasta com o maior número de estudos químicos (Pizzolatti et al. 2002, 2004; Naito \& Tohda 2006).

Além das revisões de Solereder (1908) e Metcalfe \& Chalk (1950, 1979), poucos são os trabalhos sobre a anatomia dos órgãos vegetativos das Polygalaceae. Dickison (1973) constatou que a variação na estrutura foliar, com destaque aos idioblastos traqueoidais e às glândulas crateriformes, é taxonomicamente significante em nível infragenérico para Xanthophyllum Roxb. (Polygalaceae). Eriksen (1993) verificou que a posição das glândulas foliares e nodais tem importância taxonômica a nível genérico para a família. Os estudos de Marques (1979) e Marques \& Peixoto (2007) correlacionaram a posição dos estômatos com o ambiente em que as espécies brasileiras de Polygala ocorrem. Aguiar-Dias et al. (2011) evidenciaram a ocorrência de nectários extranupciais de origem estipular ocupando posição nodal em P. laureola A. St.-Hil. \& Moq.

O presente estudo levanta as características morfológicas e descreve a anatomia foliar de cinco espécies de Polygala, com o intuito de verificar a ocorrência de padrões estruturais comuns às formações de restinga e de cerrado para as espécies em questão.

\section{Material e Métodos}

Ramos vegetativos foram coletados de indivíduos de Polygala cyparissias A. St.-Hil. \& Moq., P. laureola e P. paniculata L. ocorrentes na restinga da Praia da Fazenda, Núcleo Picinguaba, do Parque Estadual da Serra do Mar - Ubatuba (SP); P. angulata DC. ocorrente no cerrado da Estação Ecológica e Experimental de Itirapina (SP) e P. violacea Aubl. emend Marques ocorrente no cerrado da Reserva Biológica e Estação Experimental de Moji Guaçu (SP). As amostras foram identificadas pela primeira autora e os materiais testemunho, depositados no Herbário UEC, com os seguintes números de coleta: $P$. cyparissias, 715 e 724; P. laureola, 702, 704 e 710; P. paniculata, 703, 705 e 712; $P$. angulata, 744, 745 e 746 e $P$. violacea, 685, 720, 733 .

Para a caracterização fisionômica dos ambientes, adotou-se a classificação utilizada por Assis (1999) para restingas e por Gianotti \& Leitão Filho (1992) e Mantovani \& Martins (1993), para o cerrado. Os dados morfológicos seguiram a metodologia usual utilizada para a família Polygalaceae, com bases nos trabalhos de Marques (1979), Marques \& Peixoto (2007) e Aguiar et al. (2008).

Folhas adultas, completamente expandidas, foram fixadas em FAA 50 (Johansen 1940) por 24 horas, ou em formalina neutra tamponada (FNT) por 48 horas (Lillie 1965), mantidas sob vácuo e, posteriormente, estocadas em etanol $70 \%$.

Para o estudo de Microscopia Eletrônica de Varredura (MEV), as amostras da região mediana da lâmina foliar das cinco espécies, fixadas em FAA 50, foram desidratadas em série etílica. Subsequentemente, as peças foram secas pelo método do ponto crítico afixadas em suportes apropriados com fita adesiva dupla face e metalizadas com ouro. As observações e captura das imagens foram realizadas em microscópio JEOL JSM 5000LV a 20kV.

Para o estudo anatômico, amostras da região mediana da lâmina foliar das cinco espécies, e da região proximal do pecíolo de $P$. laureola, $P$. paniculata e $P$. violacea foram desidratadas em série butílica terciária (Johansen 1940) e incluídas 
em parafina purificada. As demais espécies analisadas possuíam folhas sésseis. Secções seriadas transversais e longitudinais $(10-18 \mu \mathrm{m}$ de espessura) foram coradas com safranina e azul de astra (Gerlach 1969) e as lâminas montadas em resina sintética. Folhas jovens de $P$. paniculata também foram processadas para as análises das cavidades secretoras. Os tricomas foram identificados e descritos de acordo com Theobald et al. (1979) e o indumento caracterizado segundo Radford et al. (1974).

As análises e as fotografias foram feitas com o auxílio do fotomicroscópio Olympus BX51 e filme Kodak ProImage Asa 100. Algumas secções foram observadas através de luz polarizada para evidenciar constituintes celulares de natureza birrefringente.

\section{Resultados e Discussão}

As principais características morfológicas da lâmina foliar (Figs. 1, 2) e do pecíolo (Fig. 3) das espécies investigadas estão sumarizadas na Tabela 1.

As cinco espécies estudadas ocupam áreas específicas dentro das formações vegetacionais analisadas. De acordo com isto, apresentam características distintas em relação ao seu habitat. Polygala cyparissias ocorre em duna, P. laureola na margem da capoeira, $P$. paniculata em campo brejoso localizado entre duna e capoeira, $P$. angulata ocorre no campo cerrado e $P$. violacea à margem de cerradão. Todos os indivíduos estudados recebem luminosidade ao longo de todo o dia, havendo variações quanto ao tempo de exposição de acordo com o posicionamento das folhas em relação ao sol e com o local em que os indivíduos ocorrem. A posição das folhas em relação à luminosidade difere entre as espécies de acordo com o hábito de cada uma. Polygala cyparissias apresenta hábito escandente e suas folhas ficam verticalmente posicionadas em relação ao sol; nas demais espécies, o hábito é ereto e as folhas apresentam posição horizontal, perpendicular à radiação solar. Polygala cyparissias, $P$. angulata e $P$. violacea recebem incidência luminosa durante todo o dia, enquanto que $P$. laureola e $P$. paniculata, apenas durante um período do dia.

Em vista frontal, as células epidérmicas de Polygala cyparissias, P. laureola, P. paniculata e $P$. violacea apresentam as paredes anticlinais sinuosas (Fig. 1a-b), enquanto a epiderme foliar de P. angulata (Fig. 1c-d) possui células com as paredes anticlinais retas.

Em secção transversal, observou-se que a epiderme é unisseriada (Fig. 2a-c, g-i). Em ambas as faces de P. laureola (Fig. 2i) as células epidérmicas presentes sobre a nervura central são menores que as células observadas na região intercostal (Fig. 2c) e margem foliar. Os estômatos encontram-se no mesmo nível das demais células epidérmicas em todas as espécies analisadas (Fig. 2a). Em $P$. cyparissias secreção é observada no interior de algumas células da epiderme (Fig. 2a), incluindo as células subsidiárias dos estômatos. As folhas são anfiestomáticas, exceto P. laureola que apresenta folhas hipoestomáticas (Fig. 1a-b). Os estômatos são do tipo anomocítico em todas as espécies (Fig. 1b). Para Mott et al. (1982) a organização anfiestomática possibilita maior condução de gás carbônico e capacidade fotossintetizante, o que teria valor adaptativo a ambientes com maior intensidade luminosa.

Entre as espécies aqui analisadas, $P$. laureola foi a que apresentou folha hipoestomática e mais delgada, corroborando com as observações de Burrows (2001), nas quais espécies xeromórficas da Austrália apresentam folhas anfiestomáticas mais espessas que aquelas com folhas hipoestomáticas.

Tricomas tectores unicelulares com superfície ornamentada estão presentes em todas as espécies estudadas (Fig. 1f-g). Polygala angulata apresenta indumento profuso, constituído por papilas e tricomas tectores de ápice dilatado com prolongamento lateral (Fig. 1d-e) e ausência de indumento em $P$. cyparissias, caracterizando-a como glabra (Fig. 2a). Nas demais espécies, o indumento é escasso, representado por tricomas tectores de ápice agudo em P. laureola (Fig. 1a, e), $P$. violacea, e por tricomas de ápice dilatado com prolongamento lateral em $P$. paniculata (Fig. 1f).

Kay et al. (1981) sugeriram que a epiderme papilosa pode auxiliar na reflexão dos raios luminosos, diminuindo a perda de água e auxiliando no equilíbrio fisiológico da planta; esta mesma função foi indicada para o indumento que recobre os órgãos vegetativos por outros autores (Esau 1977; Fahn 1990). Gibson (1996) considerou que grande quantidade de tricomas tectores em plantas xeromórficas é um dos caracteres morfológicos que auxilia na estratégia adaptativa da planta em habitat árido.

O mesofilo em Polygala cyparissias é homogêneo, com duas ou três camadas de células 

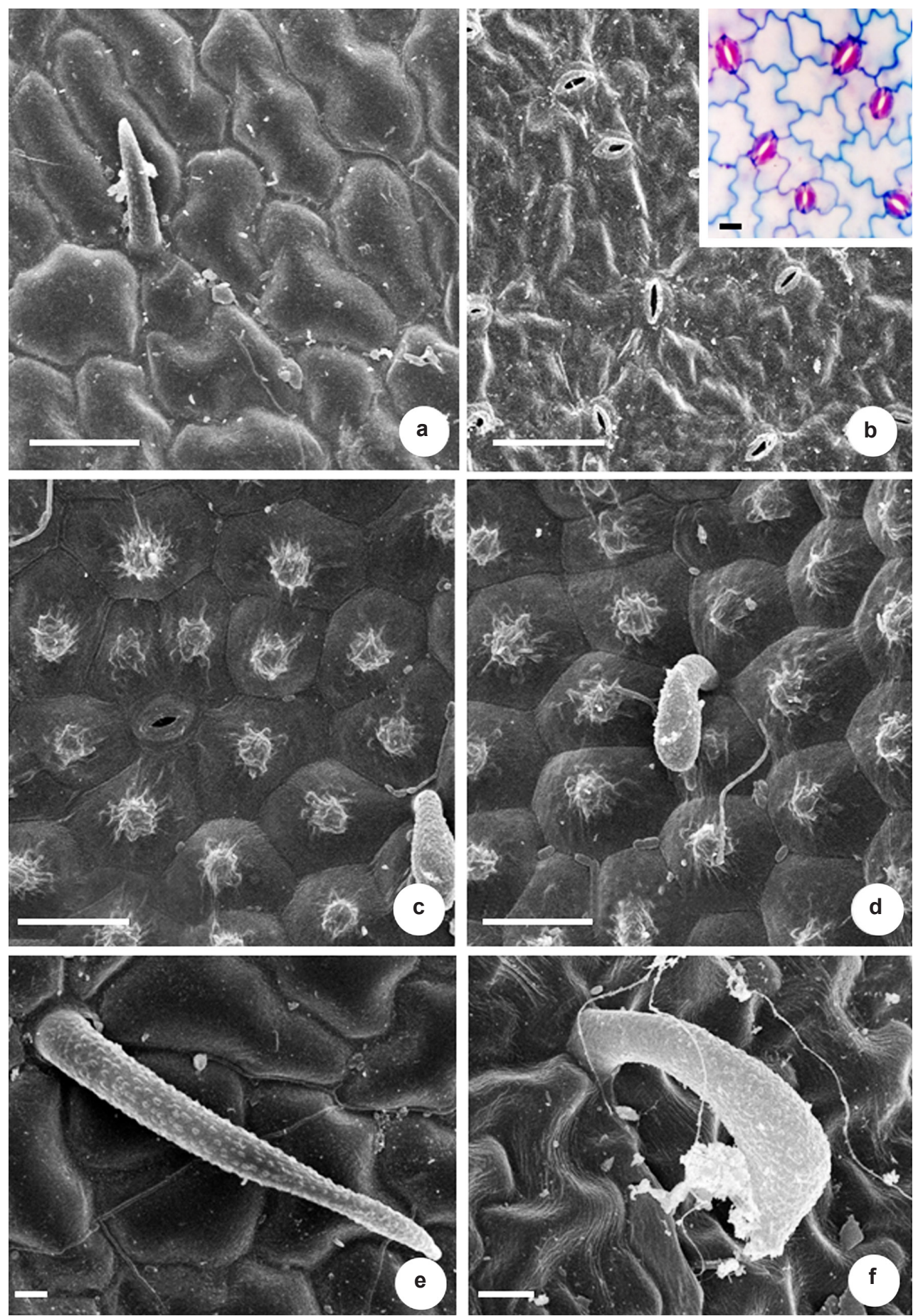

Figura 1 - Vista frontal da epiderme foliar das espécies de Polygala observadas sob microscopia eletrônica de varredura - a, c. face adaxial; b, d-f. face abaxial. a-b. Polygala laureola - note paredes sinuosas e estômatos anomocíticos (detalhe da fig. 1 b microscopia ótica).c-d. Polygala angulata - notar paredes anticlinais retas. e. Polygala laureola - notar tricoma de ápice agudo. f. Polygala paniculata; tricoma de ápice dilatado com prolongamento lateral. Escalas: a-d= $50 \mu \mathrm{m} ; \mathrm{e}-\mathrm{f}=10 \mu \mathrm{m}$. Figure 1 - Frontal view of leaf epiderm of the Polygala species observed under scanning electron microscopy - a, c. adaxial surface; b,d-f. abaxial surface. a-b. Polygala laureola - note sinuous walls and anomocytic stomata (inset of the fig. $1 \mathrm{~b}$ optic microscopy). c-d. Polygala angulata - note straight walls. e. Polygala laureola - note trichome with acute apex. f. Polygala paniculata - note trichome with dilated apex presenting a lateral extension. Bars: $\mathrm{a}-\mathrm{d}=50 \mu \mathrm{m} ; \mathrm{e}-\mathrm{f}=10 \mu \mathrm{m}$. 
parenquimáticas colunares (Fig. 2a), e dorsiventral nas demais espécies (Fig. 2b, h-i). Nestas espécies, o parênquima paliçádico é uniestratificado e o esponjoso, pluriestratificado (Fig. 2b, g-h). Em $P$. laureola, os espaços intercelulares do parênquima esponjoso são proeminentes (Fig. 2c), característica típica de espécies mesófitas (Esau 1977; Fahn 1990; Mendes \& Paviani 1997).

O mesofilo dorsiventral predomina entre os representantes da família (Solereder 1908; Metcalfe \& Chalk 1950). No entanto, Pyykkö (1966) observou a ocorrência de mesofilo homogêneo em espécies de Polygalaceae de ambientes semidesérticos, onde haveria baixa disponibilidade hídrica e alta incidência luminosa. A presença deste tipo de mesofilo em Polygala cyparissias pode estar relacionada ao ambiente (restinga) ocupado pela espécie e à posição vertical de suas folhas em relação à incidência luminosa. Shields (1951), Pyykkö (1966), Fahn \& Cutler (1992) e Burrows (2001) verificaram que as folhas que apresentam essa disposição frequentemente possuem mesofilo isobilateral ou homogêneo, como também observado em $P$. cyparissias.

Polygala paniculata apresenta cavidades secretoras no clorênquima (Fig. 2d-e), com apenas o lume das cavidades visíveis nas folhas adultas (Fig. 2e), sendo que, as células epiteliais destas cavidades e a secreção são observadas apenas nas folhas jovens (Fig. 2e), o que caracteriza essas estruturas como lisígenas. Em P. violacea, idioblastos contendo drusas ocorrem no clorênquima (Fig. 2b). Solereder (1908) e Metcalfe \& Chalk (1950) citaram a ocorrência destas estruturas nas folhas de espécies de Bredemeyera Willd. e Xanthophyllum, também Polygalaceae, mas nada mencionaram para Polygala.

As estruturas secretoras observadas nas cinco espécies estudadas são referências inéditas para as espécies brasileiras de Polygala, a saber: idioblastos na epiderme de $P$. cyparissias e cavidades lisígenas no mesofilo de $P$. paniculata. Estas estruturas já foram relatadas em folhas de espécies de Polygala por Chodat (1891), por Solereder (1908) Metcalfe \& Chalk (1950) e Eriksen (1993), que ressaltaram a importância taxonômica das glândulas foliares e nodais para os gêneros de Polygalaceae.

A presença de duas a três camadas de colênquima na margem foliar é observada apenas em Polygala laureola (Fig. 2g), enquanto as demais espécies apresentam apenas clorênquima nesta região (Fig. 2h). Sugere-se que tal característica esteja relacionada ao comprimento que as folhas de $P$. laureola apresentam, além da consistência membranácea (Tab. 1). Das cinco espécies estudadas, esta foi a espécie com o maior comprimento. A ocorrência de colênquima está diretamente relacionado a este fator, pois a função que este tecido possui está diretamente relacionado com a função de sustentar regiões que possuem crescimento primário e que estejam sujeitos a movimentos constantes (Fahn 1990). Este é um caráter comum às espécies pertencentes ao subgênero Ligustrina (Chodat) Paiva, o qual a espécie em questão está inserida (Metcalfe \& Chalk 1950).

O sistema vascular da nervura principal das cinco espécies é constituído de um único feixe vascular colateral (Fig. 2h, i) e todos os feixes colaterais de menor calibre são delimitados por uma bainha parenquimática. Estes caracteres são coerentes com os já descritos para as espécies de Polygalaceae (Solereder 1908; Metcalfe \& Chalk 1950, 1979; Pyykkö 1966), sendo um caráter conservativo para o grupo em questão.

O pecíolo apresenta contorno circular em Polygala laureola e P. violacea (Fig. 3d) e planoconvexo em P. paniculata (Fig. 3c). Nas três espécies, a epiderme é unisseriada (Fig. 3a, c, d), com tricomas tectores unicelulares. $\mathrm{O}$ tecido fundamental está constituído por várias camadas de parênquima em P. laureola (Fig. 3a) e, apenas em $P$. violacea, por várias camadas de idioblastos traqueoidais (Fig. 3d-f). O feixe vascular é único, colateral em arco tênue (Fig. 3a-d). Em P. laureola e $P$. violacea, o feixe é delimitado por um anel de fibras não lignificadas (Fig. 3b, 3e). Idioblastos traqueoidais são descritos pela primeira vez para o pecíolo de espécies de Polygala. Até o momento, estas estruturas foram mencionadas apenas para a lâmina foliar de Polygala ephedoides Burch, Badiera domingensis DC. (Solereder 1908; Metcalfe \& Chalk 1950) e para espécies de Xanthophyllum (Dickison 1973).

Polygala laureola e $P$. violacea apresentam nastismo foliar no final do dia, com movimento descendente em $P$. laureola e ascendente em $P$. violacea. O nastismo observado nessas espécies provavelmente está relacionado às características anatômicas observadas no pecíolo, como: presença de idioblastos traqueoidais e fibras não lignificadas em $P$. violacea, e a presença de várias camadas de parênquima fundamental, além de fibras 


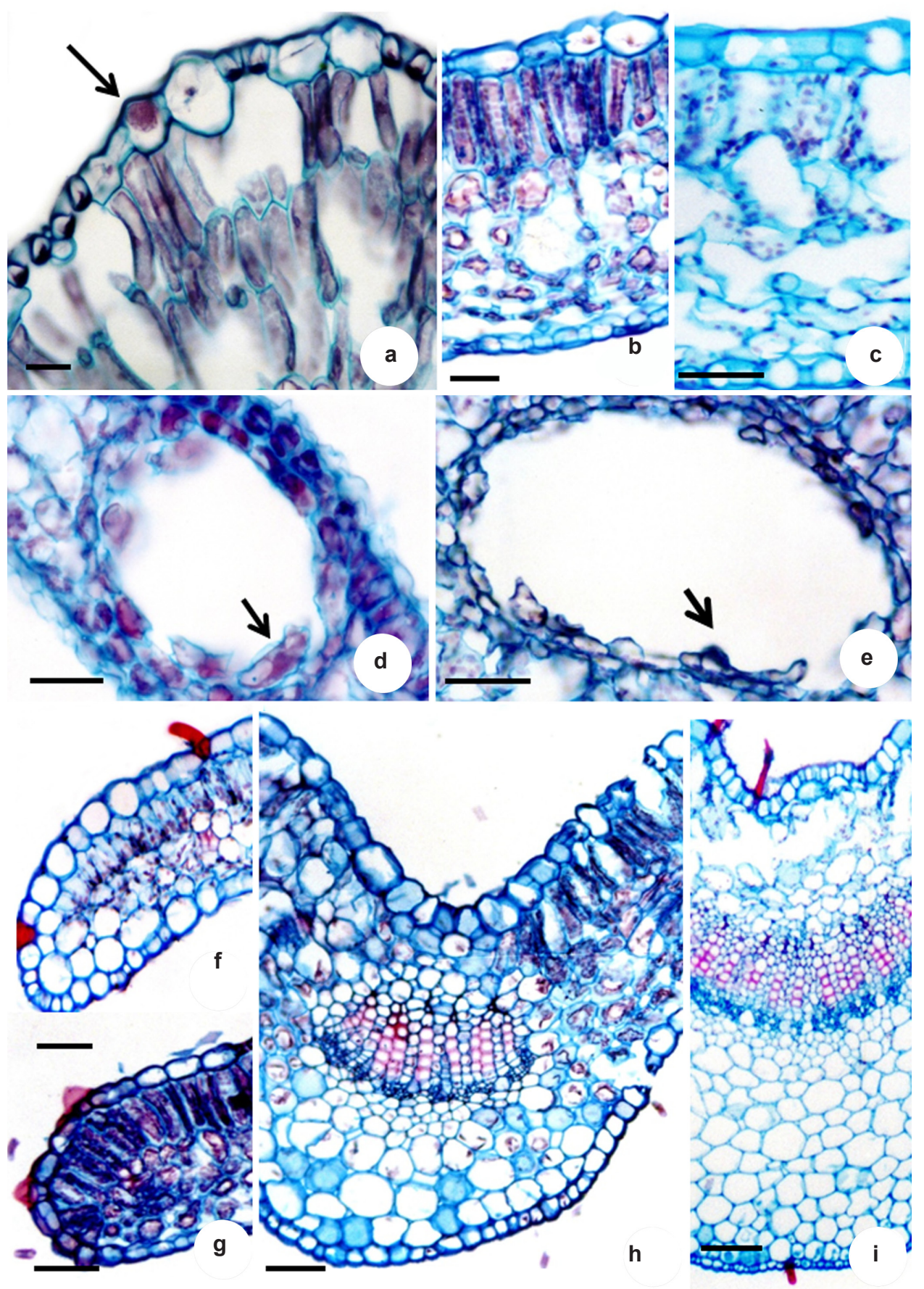

Figura 2 - Secções transversais do limbo das espécies de Polygala. a. P. cyparissias. b, g-h. P. violacea. c, f, i. P. laureola. d-e. P. paniculata. a. Idioblastos secretores na epiderme abaxial (seta) e mesofilo homogêneo. b-c. Mesofilo dorsiventral; notar drusa in Fig. 2b e em luz polarizada (detalhe). d. Cavidade secretora na folha jovem; com as células epiteliais intactas (seta). e. Cavidade secretora lisígena na folha adulta (seta). f-g. Margem; note colênquima na Fig. $2 \mathrm{f}$ e clorênquima na

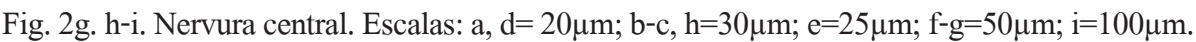

Figure 2 - Cross section of the leaf of the Polygala species. a. P. cyparissias. b, g-h. P. violacea. c, f, i. P. laureola. d-e. P. paniculata. a. Secretory idioblasts in the epidermis (arrow) and homogeneous mesophyll. b-c. Dorsiventral mesophyll; Note druse in Fig. $2 \mathrm{~b}$ and under polarized light in inset. d. Secretory cavity in young leaf; Note epithelial cells (arrow). e. Lysigenous secretory cavity in mature

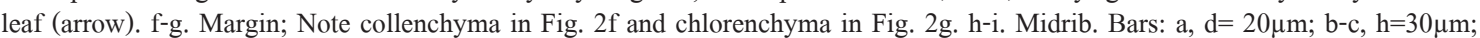
$\mathrm{e}=25 \mu \mathrm{m} ; \mathrm{f}-\mathrm{g}=50 \mu \mathrm{m} ; \mathrm{i}=100 \mu \mathrm{m}$. 


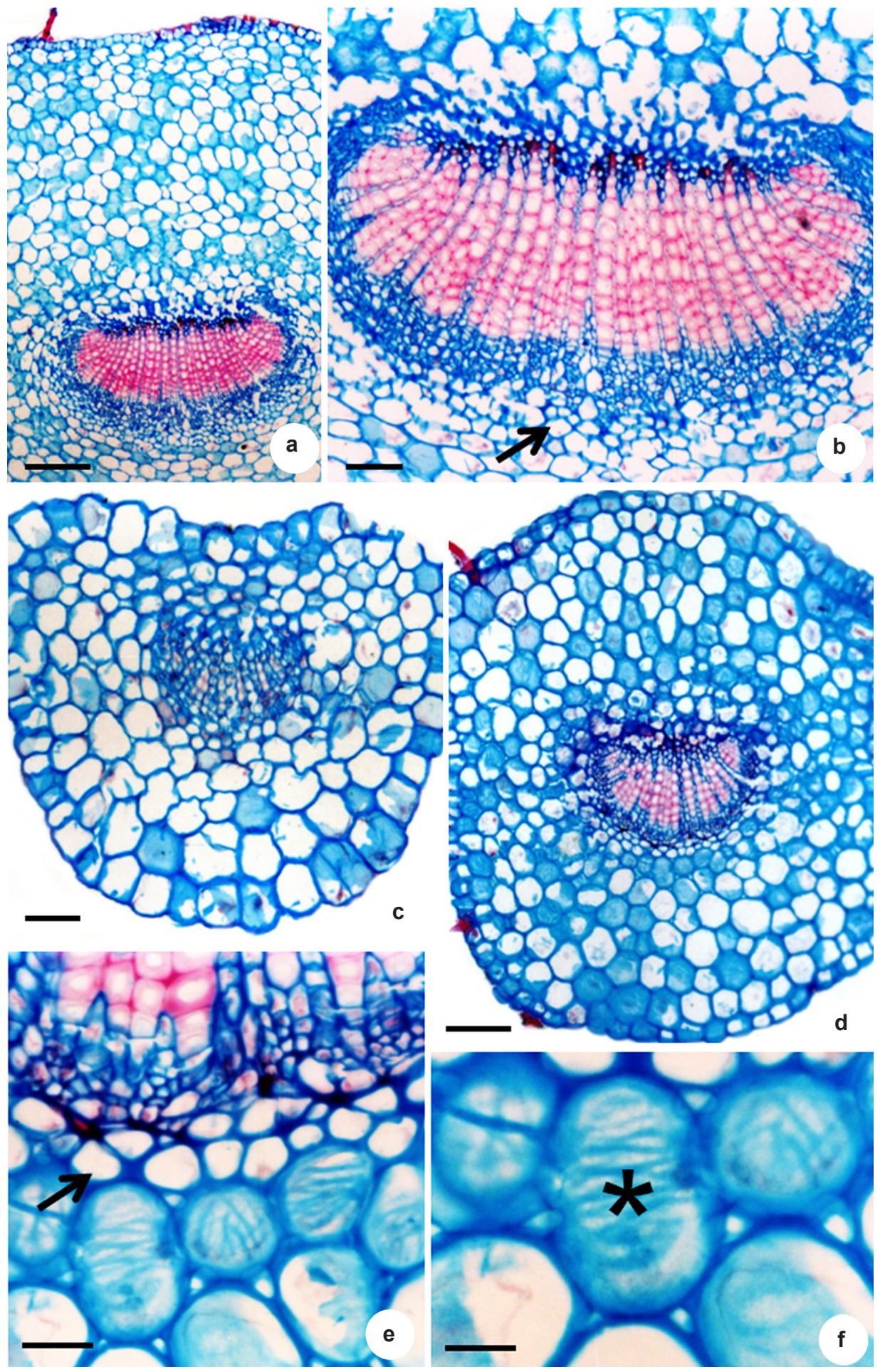

Figura 3 - Secções transversais do pecíolo das espécies de Polygala. a-b. Polygala laureola - notar a presença de fibras não lignificadas (seta); c. Polygala paniculata. d-f. Polygala violacea - note fibras não lignificadas (seta) e os idioblastos traqueoidais $(*)$. Escalas: $\mathrm{a}, \mathrm{d}=50 \mu \mathrm{m} ; \mathrm{b}, \mathrm{e}=20 \mu \mathrm{m} ; \mathrm{c}=25 \mu \mathrm{m}, \mathrm{f}=10 \mu \mathrm{m}$.

Figure 3 - Cross section of the petiole of the Polygala species. a-b. Polygala laureola - note unlignified fibers (arrow). c. Polygala paniculata. d-f. Polygala violacea - note unlignified fibers (arrow) and tracheoidal idioblasts $\left({ }^{*}\right)$. Bars: a, d=50 $\mathrm{m} ; \mathrm{b}, \mathrm{e}=20 \mu \mathrm{m} ; \mathrm{c}=25 \mu \mathrm{m}$, $\mathrm{f}=10 \mu \mathrm{m}$. 
Tabela 1 - Características morfológicas foliares das espécies de Polygala L.

Table 1 - Morphological characters of Polygala L. species.

\begin{tabular}{|c|c|c|c|c|c|}
\hline \multirow[b]{2}{*}{ Características } & \multicolumn{3}{|c|}{ Restinga } & \multicolumn{2}{|c|}{ Cerrado } \\
\hline & P. cyparissias & P. laureola & P. paniculata & P. angulata & P. violacea \\
\hline Comprimento $(\mathrm{cm}) \times$ & $0,4-1,5 \times$ & $5,0-20,0 \times$ & $1,0-3,0 \times$ & $1,0-3,0 \times$ & $3,5-4,5 \times$ \\
\hline Largura $(\mathrm{cm})$ & $0,05-0,15$ & $3,0-5,0$ & $0,1-0,4$ & $0,6-1,8$ & $0,7-2,0$ \\
\hline Área foliar reduzida & + & - & - & + & - \\
\hline Forma & acicular & $\begin{array}{l}\text { elíptica a } \\
\text { lanceolada }\end{array}$ & $\begin{array}{l}\text { linear a } \\
\text { lanceolada }\end{array}$ & $\begin{array}{c}\text { ovada a } \\
\text { obovada }\end{array}$ & $\begin{array}{l}\text { lanceolada a } \\
\text { elíptica }\end{array}$ \\
\hline Consistência & semicarnosa & membranácea & membranácea & coriácea & membranácea \\
\hline Pecíolo & - & + & + & - & + \\
\hline Contorno Cel. Epiderme & sinuoso & sinuoso & sinuoso & reto & sinuoso \\
\hline Epiderme papilosa & - & - & - & + & - \\
\hline Tricoma & - & TAG & TAD & TAD & TAG \\
\hline Estômato & anfiestomática & hipoestomática & anfiestomática & anfiestomática & anfiestomática \\
\hline Estrutura secretora & idioblasto & nectário & cavidade & - & - \\
\hline Mesofilo & homogêneo & dorsiventral & dorsiventral & dorsiventral & dorsiventral \\
\hline Idioblasto cristalífero & - & - & - & - & + \\
\hline Idioblasto traqueoidal & - & - & - & - & + \\
\hline $\begin{array}{l}\text { Colênquima } \\
\text { (nervura principal) }\end{array}$ & - & + & - & + & - \\
\hline $\begin{array}{l}\text { Elementos } \\
\text { esclerenquimáticos }\end{array}$ & - & - & - & - & - \\
\hline
\end{tabular}

Legenda: $+=$ presente; $-=$ ausente; $\mathrm{TAG}=$ tricoma de ápice agudo; $\mathrm{TAD}=$ tricoma de ápice dilatado; $\mathrm{Cel}=$ célula

Legend: += present; - = absent; $\mathrm{TAG}=$ trichome with acute apex; $\mathrm{TAD}=$ trichome with dilated apex; Cel. cell.

perivasculares não lignificadas em $P$. laureola. As características descritas para o pecíolo de $P$. laureola já foram relatadas para o pulvino de Pterodon pubescens Benth. (Fabaceae) por Rodrigues \& Machado (2004), que as evidenciaram como responsáveis pelo movimento foliar.

Os caracteres anatômicos inventariados indicam dois padrões estruturais para as folhas das espécies estudadas: mesomórficos e xeromórficos, ocorrentes tanto em restinga quanto cerrado (Tab. 1). Polygala laureola e P. paniculata (restinga) e $P$. violacea (cerrado) apresentam características mesomórficas, tais como: folhas membranáceas, epiderme unisseriada com células de paredes anticlinais sinuosas, estômatos no mesmo nível das demais células epidérmicas, mesofilo dorsiventral e ausência de elementos esclerificados além do xilema.

Polygala cyparissias (restinga) e $P$. angulata (cerrado) apresentam características xeromórficas. As folhas de P. cyparissias são semicarnosas, aciculares, com área foliar reduzida, indumento ausente e mesofilo homogêneo. Segundo Dickison (2000), a redução da razão superfície-volume é característica predominante em folhas xeromórficas. Polygala angulata possui folhas coriáceas, área foliar reduzida, células epidérmicas com paredes anticlinais retas, indumento constituído por células papilosas e tricomas tectores unicelulares. Algumas destas características (folhas semi-carnosas a coriáceas, mesofilo homogêneo, redução foliar e células epidérmicas com paredes anticlinais retas) já foram mencionadas para espécies de outras famílias que ocorrem em dunas (Andrade 1967), cerrado (Morretes \& Ferri 1959, Morretes 1966) e campo rupestre (Handro 1966, Monteiro et al. 1985). Ao estudar espécies xeromórficas do leste da Patagônia, Pyykkö (1966) relatou tricomas tectores unicelulares e mesofilo compacto para as folhas de $P$. darwiniana A.W.Benn. características estas, similares às observadas em $P$. angulata. Este 
estudo evidenciou que o xeromorfismo observado nas folhas de $P$. angulata e $P$. cyparissias pode estar associado a mais de um fator ambiental, como luminosidade, temperatura, disponibilidade hídrica, composição do solo (Morretes \& Ferri 1959; Pyykkö 1966; Fahn \& Cutler 1992) e salinidade, sendo importante a realização de estudos fisiológicos para uma melhor compreensão entre a relação das estruturas observadas com o stress hídrico e salino aos quais tais plantas estão potencialmente submetidas.

\section{Agradecimentos}

As autoras agradecem à Fundação de Amparo à Pesquisa do Estado de São Paulo (FAPESP) a bolsa de doutorado concedida à primeira autora (proc. 04/09728-8) e o financiamento no âmbito do Projeto Temático Gradiente Funcional (proc. 03/12595-7), que faz parte do Programa Biota/ Fapesp - O Instituto Virtual da Biodiversidade (www.biota.org.br). Autorização Cotec/IF 41.065/2005 e autorização Ibama/CGEN 093/2005. À Sandra Regina de Mello Barros Penze a revisão do inglês do abstract e das legendas.

\section{Referências}

Aguiar, A.C.A. \& Aranha Filho, J.L.M. 2008. A família Polygalaceae na planície litorânea de Picinguaba, Ubatuba, São Paulo, Brasil. Revista Brasileira de Biociências 6: 321-328.

Aguiar, A.C.A.; Marques, M.C.M. \& Yamamoto, K. 2008. Taxonomia das espécies de Polygala L. subg. Hebeclada (Chodat) Blake (Polygalaceae) ocorrentes no Brasil. Revista Brasileira de Biociências 6: 91-109.

Aguiar-Dias, A.C.A.; Yamamoto, K. \& Castro, M.M. 2011. Stipular extranuptial nectaries new to Polygala L.: morphology and ontogeny. Botanical Journal of the Linnean Society 166: 40-50.

Andrade, M.A.B 1967. Contribuição ao conhecimento da ecologia das plantas das dunas do litoral do estado de São Paulo. Boletim da Faculdade de Filosofia, Ciências e Letras da Universidade de São Paulo, Botânica 22:3-170.

Arruda, R.C.O; Viglio, N.S.F. \& Barros A.A.M. 2009. Anatomia foliar de halófitas e psamófilas reptantes ocorrentes na restinga de Ipitangas, Saquarema, Rio de Janeiro, Brasil. Rodriguésia 60: 333-352.

Assis, M.A.1999. Florística e caracterização das comunidades vegetais da planície costeira de Picinguaba, Ubatuba. Tese de Doutorado. Universidade Estadual de Campinas, Campinas. $254 \mathrm{p}$.
Burrows, G.E. 2001. Comparative anatomy of the photosynthetic organs of 39 xeromorphic species from subhumid New South Wales, Australia. International Journal of Plant Sciences 162: 411-430.

Chodat, R. 1891. Monographia Polygalacearum. I. Mémoires de la Société de Physique et d'Histoire Naturelle de Genève 31, suppl. 7: 1-143.

Dickison, W.C. 1973. Nodal and leaf anatomy of Xanthophyllum (Polygalaceae). Botanical Journal of the Linnean Society 67: 103-115.

Dickison, W.C. 2000. Integrative plant anatomy. Harcourt/Academic Press, San Diego. 533p.

Eriksen, B. 1993. Phylogeny of the Polygalaceae and its taxonomic implications. Plant Systematics and Evolution 186: 33-55.

Esau, K. 1977. Anatomy of seed plants. John Wiley \& Sons, New York. 550p.

Fahn, A. 1990. Plant anatomy. Pergamon Press, Oxford. $588 \mathrm{p}$.

Fahn, A. \& Cutler, D. 1992. Xerophytes. Gerbrüder Borntraeger, Berlin. 176p.

Gerlach, D. 1969. Botanische Mikrotechnik: Eine Einführung. Georg Thieme, Stuttgart. 311p.

Giannotti, E. \& Leitão-Filho, H.F. 1992. Composição florística do cerrado da Estação Experimental de Itirapina (SP). In: Sharif, R.R. (ed.). Anais do $8^{\circ}$ Congresso da Sociedade Botânica de São Paulo, Campinas 8: 21-25.

Gibbs, B.E.; Leitão-Filho, H.F; Shepherd, G. 1983. Floristic composition and community structure in an area of cerrado in S.E. Brazil. Flora, São Paulo 173: 433-449.

Gibson, A.C. 1996. Structure-function relations of warm desert plants. Springer, Berlin. 215p.

Handro, W. 1966. Escleromorfismo foliar e nutrição mineral de Gomphrena prostata (Mart.). Anais da Academia Brasileira de Ciências 38: 225-242.

Johansen, D.A. 1940. Plant microtechnique. McGrawHill, New York. 523p.

Kay, Q.O.N.; Daoud, H.S. \& Stirton, C.H. 1981. Pigment distribution, light reflection and cell structure in petals. Botanical Journal of the Linnean Society 83: $57-84$.

Lillie, R.D. 1965. Histopathologic technic and pratical histochemistry. $3^{\text {rd }}$ ed. McGraw Hill, New York. $751 \mathrm{p}$.

Mantovani, W. \& Martins, F.R. 1993. Florística do cerrado na Reserva Biológica de Moji Guaçu, SP. Acta Botanica Brasilica 7: 33-60.

Marques, M.C.M. 1979. Revisão das espécies do gênero Polygala L. (Polygalaceae) do Estado do Rio de Janeiro. Rodriguésia 31: 69-339.

Marques, M.C.M. \& Aguiar, A.C.A. 2000. Flora fanerogâmica (Parque Estadual das Fontes do Ipiranga): 128 - Polygalaceae 27: 159-164. 
Marques, M.C.M. \& Gomes, K. 2002. Polygalaceae. In: Wanderley, G.; Shepherd, G. \& Giulietti, A.M. (eds.). Flora fanerogâmica do Estado de São Paulo. Hucitec, São Paulo. Vol. 2. Pp. 229-259.

Marques, M.C.M. \& Peixoto, A.L. 2007. Estudo taxonômico do gênero Polygala L. subgênero Ligustrina (Chodat) Paiva (Polygalaceae). Rodriguésia 58: 95-146.

Mendes, I.C.A. \& Paviani, T.I. 1997. Morfoanatomia comparada das folhas do par vicariante Plathymenia foliosa Benth. e P. reticulata Benth. (Leguminosae - Mimosoideae). Revista Brasileira de Botânica 20: 185-195.

Metcalfe, C.R. \& Chalk, L. 1950. Anatomy of the dicotyledons: leaves, stem and wood in relation to taxonomy with notes on economic uses. Vol. 2. Clarendon Press, Oxford. 724p.

Metcalfe, C.R. \& Chalk, L. 1979. Anatomy of the dicotyledons. Systematic anatomy of the leaf and stem, with a brief history of the subject. $2^{\text {nd }} \mathrm{ed}$. Vol. 1. Clarendon Press, Oxford. 276p.

Monteiro, W.R.; Castro, M.M. \& Giulietti, A.M. 1985. Aspects of leaf structure of some species of Leiothrix Ruhl. (Eriocaulaceae) from the Serra do Cipó (Minas Gerais, Brazil). Revista Brasileira de Botânica 8: 109-125.

Morretes, B.L. 1966. Contribuição ao estudo da anatomia das folhas de plantas do cerrado II. Boletim da Faculdade de Filosofia, Ciências e Letras da Universidade de São Paulo, Botânica 22: 291-312.

Morretes, B.L. \& Ferri, M.G. 1959. Contribuição ao estudo da anatomia das folhas de plantas do cerrado. Boletim da Faculdade de Filosofia, Ciências e Letras da Universidade de São Paulo, Botânica 16: 5-140.

Mott, K.A.; Gibson, A.C \& O'leary, J.W. 1982. The adaptative significance of amphistomatic leaves. Plant, Cell and Enviroment 5: 455-460.
Naito, R. \& Tohda, C. 2006. Characterization of antineurodegenerative effects of Polygala tenuifolia in A beta (25-35)-treated cortical neurons. Biological \& Pharmaceutical Bulletin 29: 1892-1896.

Paviani, T.I. \& Ferreira, M.L. 1974. Anatomia foliar de Plathymenia reticulata Benth. Revista Brasileira de Biologia 49: 37-48.

Pizzolatti, M.G.; Branco, A.; Monache, F.D. \& Cristiano, R. 2002. Artefatos cumarínicos isolados de Polygala paniculata L. (Polygalaceae). Revista Brasileira de Farmacognosia 12: 21-26.

Pizzolatti, M.G., Pereira, W.S. \& Monache, F.D. 2004. A new styryl-2-pyrone derivative from Polygala sabulosa (Polygalaceae). Biochemical Systematics and Ecology 32: 603-606.

Pyykkö, M. 1966. The leaf anatomy of East Patagonian xeromorphic plants. Annales Botanici Fennici 3: 453-622.

Radford, A.E; Dickison, W.C; Massey, J.R. \& Bell, C.R. 1974. Vascular plant systematics. Harper \& Row Publishers, New York. 891p.

Rodrigues, T. \& Machado, S. R. 2004. Anatomia comparada do pulvino, pecíolo e raque de Pterodon pubescens Benth. (Fabaceae - Faboideae). Revista Brasileira de Botânica 18: 381-390.

Shields, L.M. 1951. Leaf xeromorphy in dicotyledons species from a gypsum sand deposit. American Journal of Botany 38: 175-190.

Solereder, H. 1908. Systematic anatomy of the dicotyledons. A handbook for laboratories of pure and applied botany. Clarendon Press, Oxford. 1182 p.

Theobald, W.L.; Krahulik, J.L. \& Rollins, R.C. 1979. Trichome description and classification. In: Metcalfe, C.R. \& Chalk, L. (eds.). Anatomy of the dicotyledons. Systematic anatomy of the leaf and stem, with a brief history of the subject. $2^{\text {nd }} \mathrm{ed}$. Vol. 1. Clarendon Press, Oxford. Pp. 40-53. 